\title{
A SEGURANÇA ALIMENTAR NO USO DE AGROTÓXICOS E O DIREITO DE ESCOLHA DO CONSUMIDOR
}

\author{
Camilla de Freitas Pereira ${ }^{1}$ \\ Escola Superior Dom Helder Câmara (ESDHC)
}

Theanna de Alencar Borges ${ }^{2}$

Tribunal Regional do Trabalho da 16a Regiấo (Maranhão)

\section{Resumo}

Este trabalho tem por objetivo investigar os prejuízos causados à saúde humana pelo uso abusivo de agrotóxicos e o direito de escolha do consumidor entre utilizar ou náo determinado produto por meio de informaçóes adequadas em suas embalagens. Para alcançar tal objetivo, traça-se a evolução histórica do uso dessas substâncias, e, posteriormente, demonstram-se os danos causados por seu uso. Por fim, elencam-se brevemente as normas nacionais e internacionais que cuidam da segurança alimentar em perspectiva à globalização, apontando a necessidade de interesses públicos e privados convergirem para regulá-las, incluindo questôes como direito à informação, publicidade e comercializaçáo segura de produçóes que utilizem agrotóxicos. A pesquisa utiliza-se da metodologia dedutiva, pesquisa bibliográfica, e da legislação nacional e internacional.

Palavras-chaves agrotóxicos; direito à informação; normas globais; segurança alimentar.

1 Mestre em Direito pela ESDHC. Especialista em Direito Público Global pela Universidad de Castilla-La Mancha (UCLM). Especialista em Direito Público pela Universidade Cândido Mendes (UCAM). Graduada em Direito pela Pontifícia Universidade Católica de Minas Gerais (PUC-MINAS). Advogada. E-mail: mila.frepe@gmail.com 2 Mestranda em Ciências Jurídicas pela Universidade Autónoma de Lisboa (UAL). Especialista em Derechos Humanos Laborales y Gobernanza Global pela UCLM. Especialista em Direito do Trabalho pela UCAM. Graduada em Direito pela Universidade Federal do Ceará (UFC). Juíza do Trabalho Substituta do Tribunal Regional do Trabalho da 16a Regiăo (Maranhão). E-mail: theannaborges@hotmail.com 


\section{FOOD SECURITY IN THE USE OF PESTICIDES AND THE CONSUMER'S RIGHT TO CHOOSE}

\section{Abstract}

This research paper aims to investigate harm to human health caused by abusive use of pesticides and the consumer's right to choose products using adequate information on their packages. To reach the objective the historical evolution of the employment of these substances was mapped, then damages caused by their use were demonstrated. Lastly, national and international norms regarding food security and the perspective of globalizing private relations to solve the impasse were briefly listed. Research utilized a deductive methodology, extensive bibliography, and national and international legislation. In conclusion, elaboration of public and private norms of security is necessary as a result of the right to information, guaranteeing the consumer's right to choose products containing pesticides.

Keywords: food security; global norms; pesticides, right to information. 


\section{Introdução}

O trabalho agrícola sempre foi essencial à existência do homem. É da agricultura que vem boa parte dos alimentos ou matérias primas para fabricação de bens alimentares essenciais para a subsistência de nossa sociedade. Com os avanços tecnológicos, especialmente no período posterior à segunda Guerra Mundial, que culminaram na Revolução Verde, problemas ligados à insuficiência de abastecimento agrícola diminuíram, uma vez que a utilização de biotecnologias e agrotóxicos proporcionou a produção de vegetais resistentes a fatores naturais e imunes a pragas. Os empresários do agronegócio, movidos pela ideologia capitalista, investiram nessas tecnologias, buscando maiores lucros e aumento da produção, em detrimento à saúde e segurança dos consumidores.

A modernidade trouxe alteraçôes ao modelo de exploração agrícola. Esses avanços tecnológicos incluem a mecanização de alguns processos, bem como o desenvolvimento de substâncias químicas que modificam o ciclo de vida e resistência das plantas. Porém, todo este processo de modernização tem gerado, ao longo do tempo, impactos sociais, econômicos e ambientais.

Dentre os impactos ocasionados pela evolução tecnológica agrícola, estão as doenças provocadas pelo contato humano com os agrotóxicos, por meio da manipulação ou ingestão dessas substâncias, que muitas vezes são graves e irreversíveis. A saúde da população é afetada e sua segurança encontra-se fragilizada pelos empenhos mercadológicos mundiais em alcançar margens maiores de produção e de rendimentos. O fator econômico, alicerçado em promover lucros cada vez maiores, muitas vezes amparado pelo apoio governamental, acaba por ditar as regras de saúde e segurança alimentar da população.

Nesse sentido, a ciência, responsável por essas mudanças de paradigma tecnológicos, abandona suas características empíricas cujos efeitos são previsíveis e calculáveis, produzindo riscos e vitimizando a sociedade. Apesar de muitos setores aderirem à mecanização e à utilização de agrotóxicos, o trabalho do homem é fundamental, seja por ser capaz de atuar em diferentes relevos, tornando área de cultivo, lugares em que a máquina não conseguiria alcançar, seja pela necessidade da extração e cuidado pelo homem, considerando a fragilidade do produto.

Nessa perspectiva, verifica-se um real desequilíbrio ambiental no modelo de agricultura contemporâneo, uma vez que tem gerado danos imediatos ou tardios ao meio ambiente e à saúde da população. Nesse sentido, impóe-se a urgente necessidade de abrandar ou elidir impactos relativos à utilização de agrotóxicos pelos produtores e consumidores.

Fatores como a baixa divulgação de conhecimento técnico sobre malefícios 
no uso contínuo de agrotóxicos para a população trabalhadora e consumidora, aliados ao poder econômico dos atores interessados na larga produção agrícola, levam ao cenário de verdadeira crise mundial, ameaçando a vida humana e o meio ambiente.

A partir dessa perspectiva, questiona-se a possibilidade de implementação de mecanismos que garantam o direito de escolha do consumidor sobre determinado produto.

Apesar da existência de normas internacionais regulamentando questôes ambientais, a saúde coletiva e mais especificamente a produção, o transporte e o uso de agrotóxicos e outras substâncias tóxicas, o que ocorre é que estas normas não são suficientes, além de serem frequentemente descumpridas pelos países signatários.

Diante do problema proposto, parte-se da hipótese de que há necessidade de postura internacional dos governantes diante da iniciativa privada, impondo a confecção de normas de segurança alimentar e medidas efetivas de fiscalização sobre seu cumprimento. Tais medidas garantiriam então o direito à saúde da população mundial, conscientes de consequências de consumo, a partir da escolha.

Alguns países, a exemplo dos integrantes da Uniâo Europeia, têm investido em políticas públicas no sentido de informar a população sobre a presença dos pesticidas nos produtos agrícolas. No entanto, trata-se de uma exceção diante da comunidade internacional consumidora.

O trabalho será elaborado predominantemente a partir de uma pesquisa qualitativa, partindo da análise conceitual da palavra agrotóxico, análise histórica da utilização da substância e dos danos causados à saúde. Objetiva-se a análise das falhas existentes nas normas nacionais e internacionais que regulamentam o direito à informação do consumidor. Quanto ao objeto, trata-se de uma pesquisa exploratória, isso porque serão analisados livros, artigos científicos e a legislação vigente para se chegar às respostas satisfatórias ao problema ora proposto.

A uniformização de normas internacionais para restringir e limitar o uso de substâncias de alto poder tóxico, impondo a inserção nos rótulos dos pesticidas utilizados, proporciona ao consumidor o direito à informação e escolha do produto que gostaria de consumir, assegurando sua saúde. Além disso, essas normas fomentariam a concorrência entre fornecedores para oferecer produtos mais saudáveis, com menor custo.

\section{Do conceito da palavra agrotóxico}

Existem inúmeras terminologias para intitular os agrotóxicos, o que se justifica pela diversidade de ciências que se ocupam em estudá-los, como a química, a 
biologia, a medicina, a geografia, a economia, a ecologia e a agronomia, especialmente no que concerne à açáo desses componentes na vida dos seres humanos, no meio ambiente e na economia.

As denominaçôes comumente encontradas na sociedade são as palavras agrotóxico, defensivo agrícola, praguicida, pesticida e biocida, que são utilizadas de maneira geral para indicar os mesmos produtos químicos sintetizados artificialmente para combater a ação das pragas invasoras (animais, vegetais, fungos, insetos, etc.).

Na legislação brasileira, o Ministério da Agricultura, Pecuária e Abastecimento (MAPA) prevê como denominação pertinente o termo agrotóxico, conforme Lei Federal n. 7.802, de 1989, em seu art. 2º I, que considera agrotóxicos e afins:

Os produtos e os componentes de processos físicos, químicos ou biológicos destinados ao uso nos setores de produção, armazenamento e beneficiamento de produtos agrícolas, nas pastagens, na proteção das florestas nativas ou implantadas e de outros ecossistemas e também em ambientes urbanos, hídricos e industriais, cuja finalidade seja alterar a composição da flora e da fauna, a fim de preservá-la da ação danosa de seres vivos considerados nocivos, bem como, substâncias e produtos empregados como desfolhantes, dessecantes, estimuladores e inibidores do crescimento (BRASIL, 1989).

A referida lei federal regulamentou ao longo dos artigos, o detalhamento de especificaçôes em embalagens, como fontes de intoxicações; especificação sobre riscos relativos à contaminaçóes ambientais e humanas, além de regular a publicidade sobre os produtos, e a fiscalização e responsabilização por danos causados a saúde ambiental e humana.

O Decreto n 4.074, de 2002, que regulamentou a Lei 7.802, impóe ainda a fiscalização dos produtos, tanto exportados, como importados. Além disso, formulou o conceito de produto equivalente, que determina o registro simplificado dos produtos produzidos internamente em relação aos importados (BRASIL, 2002).

Para Faria (2003), os agrotóxicos podem ser conceituados como substâncias que eliminam ou controlam pestes que prejudicam a produtividade agrícola. A palavra tem sentido amplo, uma vez que inclui todos os elementos utilizados nos agroecossistemas para eliminar pragas e doenças. Entretanto, a terminologia aponta para o sentido nocivo da substância, uma vez que é composta pelo sufixo tóxico (PASCHOAL, 1979).

A nomenclatura defensivo agrícola, utilizada pelo setor industrial, dá o sentido de que essas substâncias são protetivas aos elementos agrícolas, protegendo 
da ação de pragas, o que considera seu intuito econômico, ao reduzir danos à produçáo e desconsiderando questóes relacionadas à saúde. Trata-se de uma rede econômica estruturada e muito lucrativa, conforme observam Porto e Milanez (2009 apud ALMEIDA; CERINO, 2018, p. 5):

Neste processo de modernizaçâo da agricultura, conduzido pelos interesses de grandes corporaçôes transacionais, configurou-se o agronegócio enquanto um sistema que articula o latifúndio, a indústria química, metalúriga e de biotecnologia, o capital financeiro e o mercado (FERNANDES; WELCH, 2008), com fortes bases de apoio no aparato político institucional e também no campo científico e tecnológico. Este sistema ampliou a monocultura, a concentração de terras, de renda e poder político dos grandes produtores. Elevou também a intensidade do trabalho, a migração campo-cidade e o desemprego rural. Por outro lado, a apropriação dos frutos dessa produtividade reverteu-se em aumento dos lucros capitalista, para os grandes proprietários rurais e as multinacionais envolvidas.

Os danos à saúde causados por essas substâncias atingem milhares de pessoas. E embora saibamos que a tentativa humana de controlar a natureza é uma prática antiga, notada pela intervenção do homem na agricultura, visando à própria sobrevivência, essas substâncias "afetam na qualidade ou quantidade de lavouras, nos alimentos, rações, flores, madeiras, forragens, fibras; tanto na produção, como na armazenagem ou transporte destes produtos, provocando perdas econômicas consideráveis" (MORAGAS; SCHNEIDER, 2003, p. 27).

No Brasil, o uso dos agrotóxicos teve expressivo significado com a Revolução Verde na década de 60, o que será tratado no próximo capítulo.

\section{Breve evolução histórica da utilização dos agrotóxicos}

A agricultura é prática de sobrevivência desde a antiguidade, identificada há cerca de dez mil anos em regiôes da África e Ásia. Naquele período, técnicas foram aprimoradas para obtenção de melhores safras. No entanto, não ocorreram muitos avanços, uma vez que as técnicas e instrumentos permaneceram muito precários (MORAGAS; SCHNEIDER, 2003).

No período medieval, a agricultura orgânica era a prática europeia e mundial até o ano 1500. Isso ocorria devido à influência exercida pela autoridade da igreja 
e de Aristóteles, em que as investigaçóes de cientistas medievais se destinavam a vários fenômenos naturais (BORSOI et al. 2014). A partir dos séculos XVI e XVII, toda a estrutura científica medieval se rompeu e foi substituída pela concepção da mecanização, influenciada pelas ideias científicas de Copérnico, Galileu, Newton e Einstein (PINOTTI; SANTOS, 2013). Há, entretanto estudos que relatam que já no século XVI nos Estados Unidos e Europa, utilizava-se da nicotina e piretros (inseticida natural obtido da trituração das flores de algumas plantas pertencentes à família Compositae, gênero Chrysanthemum) extraídos de plantas, como pesticida (ALMEIDA; CERINO, 2018).

A partir do século XVIII ocorreu a primeira Revolução Agrícola na Europa, trazendo consigo uma modernizaçáo na agricultura, implantando o sistema de rotaçâo de culturas. Esse sistema consistia em alternar anualmente o plantio de forrageiras (para o gado) e o plantio de leguminosas. Assim “[...] a criação de animais supria a agricultura com esterco natural para a fertilizaçáo dos solos e a agricultura sustentava a alimentaçáo dos rebanhos que também forneciam leite e carne, entre outros produtos, bem como eram utilizados no preparo da terra e na semeadura" (MORAGAS; SCHNEIDER, 2003, p. 33).

O homem tem empreendido luta constante contra as pragas que competem pelo alimento e são causa de transmissão de doenças. A ação de alguns compostos inorgânicos é conhecida há muito tempo, assim, por exemplo, as aplicaçóes de compostos sulfurados (antes do século XI), derivados do arsênio (século XVII), cloreto de mercúrio (século XVIII) e sais de cobre (século XIX) foram práticas habituais. Por outro lado, a utilização de compostos orgânicos com propriedades pesticidas era reduzida basicamente à aplicação de inseticidas naturais, como por exemplo a nicotina (século XVII), a rotenona ou pyretrum (extraído da flor de crisântemo), este último na segunda metade do século XIX.

Em 1930, ocorreu a introdução dos primeiros pesticidas orgânicos sintéticos, os alquiltiocianatos. No entanto, não resta a menor dúvida de que o primeiro a demonstrar ampla eficiência inseticida foi o diclorodifenil-tricloroetano, o DDT, sintetizado em 1939 por Müller e manufaturado em 1943 (NUNES; RIBEIRO, 1999, p. 1).

O sistema de rotação de culturas foi rompido no final do século XIX, ocasião em que ocorreu a segunda Revolução Agrícola, influenciada pelas descobertas científicas no campo da química, mecânica e da engenharia genética.

Nessa época, foram criados os fertilizantes artificiais, máquinas, implementos 
e sementes melhoradas, produzidas em escala industrial. Tais criaçóes tinham por objetivo alcançar elevada produtividade com base na monocultura, intensa mecanização, fertilização sintética, e defesa fitossanitária com uso de agrotóxicos. A partir da década de 1930, desenvolveram-se, também, compostos químicos organossintéticos que operavam no controle de organismos nocivos às plantas, também chamados de biocidas (MORAGAS; SCHNEIDER, 2003, p. 33).

Esse modelo, desde o início, sofreu severas críticas quanto ao seu potencial nocivo ao meio ambiente e ao ser humano, conforme explana Besson a seguir:

Com os problemas de erosão e de fertilidade dos solos, Albert Howard (1873-1947) pensa que está acontecendo uma "doença de civilização". [...] Hans Christian Müller (1891-1988) considera que as ameaças que pesam sobre a existência de pequenos e médios campesinos constituem um perigo para a sociedade como um todo. Ele chama à sabedoria cristâ, enquanto seu colega Hans Peter Rusch (1906-1977) trabalha na agrobiologia com a ideia do "Todo vivo" [...]. Masanobu Fukuoka (1913-2008) colocou toda sua busca de uma agricultura natural no olhar de um confronto filosófico entre os princípios da cultura oriental e a abordagem científica: a questão agrícola é considerada dentro de uma concepçấo do mundo [...]. Rudolf Steiner [o fundador da agricultura biodinâmica] (1861-1925) é o pai da antroposofia, um movimento esotérico (BESSON, 2009 apud BRIGNOL, 2012, p. 9).

A partir de 1940 ocorreu uma evolução tecnológica e industrial motivada pela guerra. Nessa época, os produtos e as técnicas desenvolvidas na guerra começaram a influenciar e impactar no setor agrícola europeu e norte-americano, substituindo ou simplificando o processo de fertilização natural, preparo da terra, plantio, tratos culturais, colheita e reduzindo a contratação de mão de obra.

Nesse contexto, o objetivo inicial no desenvolvimento desses produtos químicos era a destruição da colheita dos inimigos, ou seja, era utilizado como artifício bélico para ceifar a vida do rival. "[...] Após a guerra, estes produtos ganharam nova roupagem para ser empregados na agricultura. Assim, não haveria prejuízo para fabricantes desses produtos químicos, uma vez utilizados na agricultura, continuariam a gerar lucros à indústria" (ALMEIDA; CERINO, 2018, p. 3).

$\mathrm{O}$ foco da pesquisa no desenvolvimento dos agrotóxicos à época era no sentido de que as sementes modificadas e desenvolvidas nos laboratórios possuíssem alta resistência a diferentes tipos de pragas e doenças. Assim, o plantio, aliado à utilização de agrotóxicos, fertilizantes, implementos agrícolas e máquinas, 
aumentaria significativamente a produção agrícola (SERRA et al., 2016), como esclarecem Hupffer e Pol (2017, p. 44):

Ao abordar a questấo, Jain (2010, p.10) explica que o período pós-Segunda Guerra Mundial foi profícuo para várias descobertas científicas que favoreceram o processo de industrialização do setor agrícola. Entre as inovaçóes, o autor destaca "a teoria de Liebig, relativa à utilização de fertilizantes inorgânicos para reabastecer nutrientes removidos dos solos pela cultura de plantas; a Lei de Mendel que forneceu a base para o melhoramento científico das plantas"; a síntese do DDT realizada por Paul Müller, que contribuiu para a criação de vários pesticidas orgânicos para a proteção de culturas e para a produçáo em escala industrial de implementos e máquinas agrícolas modernas.

Antes de serem utilizados em larga escala na agricultura, os agroquímicos permitiram o controle de graves doenças que vitimaram milhóes de pessoas em anos e décadas anteriores. Assim, via-se nos agroquímicos o potencial para controlar doenças e predadores de diversos sistemas de cultivo, bem como os ganhos econômicos com a redução da mão de obra na produção agropastoril e auxílio no combate à erosão dos solos.

No caso dos Estados Unidos, após saírem vencedores da Segunda Guerra Mundial, houve um período de grande desenvolvimento urbano e rural, com aumento descontrolado da populaçáo, que ficou conhecido como baby boom, o que ocorreu também nos países a ele aliados, entre 1946 e 1964. Esses acontecimentos ocasionaram uma demanda maior por alimentos para a população norte-americana e para os países carentes ou destruídos pela guerra (MOURA, 2013).

A partir de então o uso dos agrotóxicos começou a se disseminar pelo mundo sob o pretexto de eliminar a fome mundial, surgindo a chamada Revolução Verde. Os resultados expressivos dessa evolução ocorreram entre 1960 e 1970, quando países em desenvolvimento tiveram uma significativa melhora em sua produtividade agrícola. Esses impactos são relatados por Serra et al. (2016, p. 3):

Ainda antes do término da Segunda Guerra Mundial, em cujo momento pode-se observar a formação de um conjunto de variáveis técnicas sociais, econômicas e políticas para a formação da Revolução Verde, instituiçôes privadas, como a Rockfeller e a Ford, vendo na agricultura uma boa chance para reproduçấo do capital, começaram a investir em técnicas para o melhoramento de sementes, denominadas Variedade de Alta Produtividade (VAP), no México e nas Filipinas. Dentre as sementes, destacam-se o 
trigo, o milho e o arroz, sementes que são a base da alimentação da população mundial. O grupo Rockefeller, sediado em Nova Iorque, utilizando um discurso ideológico de aumentar a produção de alimentos para acabar com a fome no mundo, expandiu seu mercado consumidor, fortalecendo a corporação com vendas de pacotes de insumos agrícolas, principalmente para países em desenvolvimento como Índia, Brasil e México. Ainda nesse contexto do final da Segunda Guerra Mundial, empresas de produtos químicos responsáveis por abastecer a indústria bélica norte-americana começaram a incentivar a produçâo e o uso de agrotóxicos como herbicidas, fungicidas, inseticidas e fertilizantes químicos. Paralelamente a esse incentivo do uso de agrotóxicos, começou a ser adotado, também, o uso de maquinário pesado no campo.

A Revolução Verde foi iniciada em 1966, em uma Conferência realizada em Washington. A justificativa de sua criação estava embasada na eliminação da fome mundial por meio de um modelo de produção agrícola fundamentado no uso de sementes híbridas, mecanização da produção, utilizaçáo de insumos industrializados e monocultura, substituindo assim a tradicional estrutura existente de produção, por um modelo mais homogêneo e tecnológico (EHLERS, 1996).

Essas tecnologias inovadoras se alastraram pelo mundo, sendo a maioria delas alicerçada no uso extensivo de agentes químicos, o que proporcionava aos agricultores o aumento da produtividade por meio do controle de doenças e proteção contra insetos e outras pragas (RIBAS; MATSUMURA, 2009).

Nesse sentido, a partir da década de 70 a produçấo de alimentos cresceu de forma imprudente, com fundamento na garantia de que não faltassem alimentos no futuro (BRASIL, 2017). No entanto, ao mesmo tempo em que o uso dos agrotóxicos trazia esse benefício, a populaçáo começou a perceber a ocorrência de efeitos indesejados e difíceis de ser controlados, como a degradação do solo, das águas, dos animais e da vegetação. Essa constatação provocou uma corrida das empresas para pesquisar, desenvolver e lançar novos produtos que tivessem como objetivo principal a solução de problemas que elas mesmas tinham causado (VELASCO; CAPANEMA, 2006).

Ainda com relação aos Estados Unidos, esse país passou a utilizar de forma abusiva os agrotóxicos na cidade e no campo e, por conseguinte, graves problemas ambientais e de saúde pública começaram a surgir, sendo ocultados da população que consumia os produtos constantemente. $\mathrm{O}$ crescimento no consumo da substância foi responsável por transformar um discreto grupo de empresas, num 
dos mais prósperos aglomerados multinacionais do mundo, influenciando alguns países da Europa a seguirem o mesmo caminho (MOURA, 2013).

Neste contexto, Beck (2011) explica que no início do uso de agrotóxicos, a sociedade estava interessada apenas em seus benefícios, pouco se importando com as reaçôes que poderiam causar no corpo humano e no meio ambiente. A própria sociedade produz para si os riscos que escapam à percepçáo, tendo consequentes ameaças sociais, conforme descreve a seguir:

Os antigos "efeitos colaterais imprevistos" tornam-se efeitos principais visíveis, que ameaçam seus próprios centros causais de produção. A produção de riscos da modernização acompanha a curva do bumerangue. A agricultura intensiva de caráter industrial, fomentada com bilhóes em subsídios, não somente faz aumentar dramaticamente em cidades distantes a concentração de chumbo no leite materno e nas crianças. Ela também solapa de múltiplas formas a base natural da própria produção agrícola: cai a fertilidade das lavouras, desaparecem espécies indispensáveis de animais e plantas, aumenta o perigo de erosão do solo.

$[\ldots]$

Isto é diferente no caso da crise ecológica. Ela também compromete as bases naturais e econômicas da agricultura e, em decorrência, o abastecimento de toda populaçãa. Sáo visíveis, nesse caso, efeitos que repercutem não apenas no âmbito da natureza, mas também nos cofres dos ricos e na saúde dos poderosos. À boca larga e independente de filiação partidária, o que se ouve são tons estridentes, apocalípticos (BECK, 2011, p. 45).

No Brasil, apesar de muitas substâncias ativas não serem permitidas, esses resíduos ainda são encontrados nos alimentos. Por outro lado, o uso abusivo de agrotóxicos, mesmo que de forma autorizada, tem produzido alimentos altamente contaminados, acima dos limites tolerados pela legislação, segundo a Anvisa (BRASIL, 2016).

Um fator que dificulta a implementação de políticas públicas para melhor informação da população em caráter mundial é que a análise de resíduos de agrotóxicos em amostras ambientais ou de alimentos, principalmente quando o número de contaminantes é elevado, tem alto custo financeiro e tecnológico. Exige-se a aplicação de técnicas elaboradas e onerosas, que também é agravada pela grande diversidade de agrotóxicos no comércio e pelo escasso número de dados dos produtos utilizados na lavoura, o que acaba por demandar o teste em vários padróes e diferentes metodologias analíticas (FARIA, 2003). 


\section{Dos danos à saúde e ao meio ambiente pelo uso de agrotóxicos}

A Organização Mundial de Saúde, atenta aos altos índices de contaminação causados pelo uso de agrotóxicos, afirma tratar-se de um grave problema de saúde pública, uma vez que, para cada caso atestado, constata-se a presença de outros cinquenta subnotificados, o que levaria a um resultado de, aproximadamente, quatrocentos e cinquenta mil casos (HUPFFER; POL, 2017).

Constatam Carneiro et al. (2015) que, um terço dos alimentos consumidos cotidianamente pelos brasileiros está contaminado pelos agrotóxicos, de acordo com pesquisa de amostras coletadas nos 26 estados brasileiros.

Ainda, de acordo com Branger, Teodoro e Silveira (2012), os dados da Organização Mundial de Saúde atestam que as intoxicaçôes agudas por agrotóxicos atingem cerca de três milhôes de produtores por ano, com 2,1 milhóes de casos só em países como Brasil, Chile, México. Com aumento de casos em outros países que se encontram em crescente industrialização e elevação de produção, alcançando o patamar de 20.000 mortes por ano em todo o mundo.

Entretanto esses dados estatísticos podem ser bem maiores, pois não são contabilizadas todas as outras intoxicaçóes mais moderadas, que não apresentem sintomas ou ainda, que demonstrem consequências em longo prazo. Esse mesmo órgão avalia que $70 \%$ das intoxicaçôes agudas por exposição ocupacional são causadas por inseticidas organofosforados (STOPPELLI; MAGALHAES, 2005). Os comprometimentos à saúde com a exposição contínua aos agrotóxicos podem variar intensamente, dependendo de características do indivíduo, como, por exemplo, estado nutricional, idade e sexo.

Vários países têm se debruçado em pesquisas a respeito desses componentes, implantado programas de análise de resíduos nos alimentos, como verificado pela European Comission (2004 apud STOPELLI; MAGALHĀES, 2005, p. 94-95):

Nos Estados Unidos, numerosos programas de análises de resíduos têm sido implantados, podendo-se destacar o programa do Departamento de Agricultura dos Estados Unidos (USDA), o programa da Associação Nacional dos Alimentos Processados (NFPA) e o programa da Administração de Drogas e Alimentos (FDA). [...]. Dos grupos de amostras analisadas vindas do mercado interno, todas continham resíduos de agrotóxicos, porém apenas os grupos de amostras de origem vegetal (grãos, frutas e vegetais) continham resíduos de agrotóxicos acima do nível tolerado. Já as amostras vindas do mercado externo 
apresentaram índices de contaminaçáo acima do tolerado em amostras do grupo de vegetais e em amostras de peixe. A União Europeia possui trabalho similar de análise de alimentos. [...] Os resultados obtidos mostraram que $54 \%$ das amostras estavam livres de pesticidas, enquanto $37 \%$ apresentaram níveis residuais abaixo do limite tolerável. Cerca de $6 \%$ das amostras acusaram a presença de resíduos de agrotóxicos acima do nível permitido, sendo a maior incidência em frutas e verduras. O nível de resíduos detectados no último ano foi o maior se comparado com os índices de contaminação dos seis anos anteriores.

Os danos à saúde dessas pessoas são incalculáveis, tanto para os consumidores dos produtos agrícolas, quanto para o trabalhador da lavoura que está diretamente exposto ao produto químico. Outrossim, os efeitos dessas substâncias no corpo humanos podem variar de indivíduo para indivíduo devido "[...] à ampla gama de princípios ativos nos pesticidas, os efeitos tóxicos clínicos podem variar significativamente de indivíduo para indivíduo, bem como devem ser levados em conta os sintomas, devido a fatores ambientais" (HUPFFER; POL, 2017, p. 49).

A literatura atesta que o problema é ainda mais grave no caso de exposição múltipla, nos dizeres de Londres (2011, p. 29):

Outro problema ainda pouco estudado sobre a utilizaçấo de agrotóxicos é a exposição múltipla a agrotóxicos. Ocorre quando há contato do agricultor ou manipulador a vários tipos de agrotóxicos com compostos químicos diferentes. De acordo com Flavia Londres: comumente esta exposição acontece ao longo de vários anos, com algumas manifestações agudas de intoxicação por algum veneno específico. Os toxicologistas já sabem que a toxicidade das misturas não é equivalente a soma das atividades tóxicas de cada produto. Os produtos podem interagir entre si e produzir efeitos adversos diferentes e por vezes mais graves do que aqueles provocados separadamente por cada um dos diferentes produtos. Existe atualmente uma preocupação especial com relação a "misturas involuntárias" entre produtos. Isto acontece porque alguns venenos podem persistir no meio ambiente por longos períodos. Assim, o agricultor pode, no campo, ficar exposto a diferentes produtos que tenham sido aplicados em ocasióes distintas.

No cenário mundial, o mercado de agrotóxicos cresceu, entre 2000 e 2010 , cerca de 93\% (SILVA NETO, 2017). No Brasil, no ano de 2016, foram notificados 3.319 casos de intoxicaçóes por agrotóxicos, o que corresponde a 5,7\% do 
total de intoxicaçóes. Ainda com relação ao Brasil, sua posição de destaque no cenário mundial como um dos maiores consumidores de agrotóxicos do mundo se evidencia com os dados de comercialização por área plantada que passou de $10,32 \mathrm{Kg} /$ ha para 16,44 Kg/ha, no curto período de 2013 a 2017 (SILVA NETO, 2017).

Os agrotóxicos penetram no organismo do homem pela inalaçáa, aspiração, vias digestivas, cutâneas/dérmicas e oculares (OPAS, 2018). O nível de intensidade de intoxicação no organismo humano pode ser aguda, subaguda e crônica; sendo analisados fatores como o potencial de toxidade do produto e o tempo de exposição. Assim, a intoxicação pode ocorrer de forma moderada, média ou grave, dependendo da quantidade de veneno absorvido.

A exposição aos agrotóxicos pode gerar consequências leves, intermediárias ou gravíssimas à saúde humana. Os danos mais comuns ao homem estâo relacionados com a memória e movimentos, sistema nervoso, sistema respiratório, sistema endócrino, hormônios, podendo ocasionar câncer, esterilidade, reaçôes alérgicas e acidentes de trabalho, como dispóe a Organização Pan-americana da Saúde:

Vários fatores participam de sua determinação, dentre eles os fatores relativos às características químicas e toxicológicas do produto, fatores relativos ao indivíduo exposto, às condiçôes de exposiçâo ou condiçôes gerais do trabalho. Características do produto: características toxicológicas, forma de apresentação, estabilidade, solubilidade, presença de contaminantes, presença de solventes, etc. Características do indivíduo exposto: idade, sexo, peso, estado nutricional, escolaridade, conhecimento sobre os efeitos a medidas de segurança, etc. Condições de exposição: condiçôes gerais do trabalho, frequência, dose, formas de exposição, etc. As características clínicas das intoxicaçôes por agrotóxicos dependem, além dos aspectos acima citados, do fato de ter ocorrido contato/exposiçấo a um único tipo de produto ou a vários deles (OPAS, 1996, p. 23).

No que diz respeito à saúde do trabalhador agrícola, há uma exposição direta por um longo período. Especificamente no Brasil, segundo Pignati (2018), dentre as intoxicaçóes exógenas, as referentes aos agrotóxicos atingem o segundo lugar, ostentando a mais elevada letalidade em relação a todos os agentes tóxicos. Esta contaminação relaciona-se com a falta de informação técnica e com baixos níveis de alfabetização, conforme Almussa e Schimidt (2009).

Apesar de alguns países do mundo possuírem legislaçóes mais rígidas, a utilização de agrotóxicos e as doenças por eles ocasionadas são um problema global, 
gerando pesquisas sobre o câncer ocupacional e ambiental em diversos países. Segundo Stopelli e Magalhães (2005), em Bogotá, na Colômbia, num estudo feito em 306 mulheres, todas da mesma idade, 153 delas foram diagnosticadas com câncer de mama, e as demais 153 estariam fazendo exames de controle. Avaliou-se a associação entre essa neoplasia e níveis de diclorodifenildicloroeteno (DDE pesticida organoclorado) no sangue, e a pesquisa concluiu que há um aumento do risco relativo de 1,95 pela exposiçáo a essa substância.

A criação de um sistema nacional e internacional de normatização e fiscalização é uma medida que garantiria maior segurança aos consumidores de alimentos, bem como aos trabalhadores e a seus familiares, e observaria toda a cadeia produtiva.

\section{A segurança alimentar e nutricional e o direito à informaçáo do homem mediante o consumo de agrotóxicos}

A garantia de segurança alimentar, segundo a Food and Agriculture Organization (FAO - Organização das Naçôes Unidas para a Agricultura e Alimentação), existe "[...] cuando todas las personas tienen todo momento acceso físico y económico a suficientes alimentos inocuos y nutritivos para satisfacer sus necessidades alimentícias y sus preferencias encuanto a los alimentos a fin de llevar una vida activa y sana"3 (FAO, 1996).

A segurança alimentar não se funda apenas no direito de acesso aos alimentos quantitativamente, mas também na qualidade dos alimentos postos à disposição do consumidor. Nesse sentido o consumidor possui o direito de saber o que está consumindo, em especial, quando o produto é originário do uso de agrotóxicos ou quando se trata de sementes transgênicas.

A partir daí, o consumidor, em posse das informaçóes necessárias e dispostas em uma linguagem adequada, para fácil entendimento, poderia exercer o direito de escolha entre consumir ou não determinado produto. Assim, atrairia para si a responsabilidade pelo risco dos possíveis danos que tais alimentos poderiam provocar à sua saúde, de acordo com suas escolhas baseadas no livre arbítrio.

A rotulagem de alimentos é uma medida de segurança alimentar. Isso porque o consumidor, informado das substancias presentes no alimento, tomaria a suas decisóes individuais pelo consumo (HUPFFER; POL, 2017).

O direito à informação é um tema que não está expressamente previsto em

3 Existe segurança alimentar quando todas as pessoas têm sempre acesso físico e econômico a alimentos seguros e nutritivos suficientes para satisfazer as suas necessidades alimentares e preferências alimentares, a fim de levar uma vida ativa e saudável (traduçao livre). 
muitas Constituiçóes do mundo. No entanto, frequentemente discute-se sobre transparência ou quais os princípios que regulariam a publicidade; e a jurisprudência de cortes constitucionais considera a transparência como condiçáo dos princípios básicos do Estado constitucional democrático (PERLINGEIRO, 2014). Além disso, em legislaçóes de vários países, é comum a previsão ao direito à informação.

A situação é ainda mais alarmante quando se trata do direito à informação quanto aos alimentos contendo agrotóxicos. Isto porque o cidadão comum náo tem capacidade técnica para buscar sozinho dados sobre a quantidade, nocividade à saúde ou qualificação da substância tóxica. Esses dados devem ser fornecidos pelo produtor ou comerciante dos alimentos, de forma precisa.

No cenário internacional, existem vários documentos e tratados assegurando a informação às pessoas. Em 1985 a Assembleia Geral das Naçôes Unidas, por meio da Resolução n. 30/248, art. $3^{\circ}$, determinou, entre outras proteçóes, a necessidade de promover a proteçáo contra riscos para a saúde e segurança e o acesso dos consumidores à informação. O Inciso "c" do referido artigo, claramente dispóe que "o acesso dos consumidores a informaçóes adequadas que lhes permitam fazer escolhas informadas de acordo com os desejos e necessidades individuais" (UNITED NATIONS, 2003a). No mesmo ano, o referido órgão aprovou também a Resolução n. 39/248, acrescentando ao consumidor o direito à satisfação das necessidades básicas, o direito à reparação, o direito à educação do consumidor, bem como o direito a um ambiente saudável (UNITED NATIONS, 2003b).

Em 2008, a Comissão Jurídica Interamericana aprovou um documento sobre os Princípios do Direito de Acesso à Informação, com uma declaração contendo dez dispositivos que regem o direito à informaçáo, considerado um direito humano fundamental a ser aplicado a todos os órgãos públicos.

Com a globalização e os acordos internacionais econômicos, produções alimentícias transitam entre os países, proporcionando uma facilidade no consumo dos produtos provenientes de diversos territórios, que são facilmente encontrados nas gôndolas dos mercados locais. Diante disso, surge a necessidade da implementação de políticas particulares e públicas em âmbito global, garantindo ao consumidor informaçóes precisas, claras e suficientes para o exercício do seu direito de escolha. A assunção do risco seria transferida diretamente ao consumidor que teria a opção de acordo com suas convicçôes, modo de vida, entre outros fatores individuais.

Nesse sentido, Martín (2016) defende uma legislação penal global para regulamentar a segurança alimentar, conforme a seguir: 
Food regulation, and thus food criminal Law, revolves around the protection of three major legal interests: food security, food safety and consumers' economic interests. Over the last two decades all of theses legal interests have undergone a very significant internalization process. [...]

Food security amounts to a global legal interest, since it is included in the universal human rights system under Article 11 of the United Nations International Covenant on Economic, Social and Cultural Rights (ICESCR). Its core guarantees the right to be free from hunger and access to adequated food, which involves the right to healthy nutrition. The consolidation of free trade as pillar of globalization has led to an intense international regulation of food safety that sets the boundaries for national and regional legislators. In addition to safeguarding health, it is aimed at preventing that domestic legislation unjustifiably hinders free trade on the grounds of food safety protection. Thus, the main promoters of the aforementioned legislation are, in addition to the food Agriculture Organization (FAO), the World trade Organisation (WTO) and corporate self- regulation ${ }^{4}$ (MARTÍN, 2016, p. 17).

A cooperação pública-privada tem relevância como mecanismo para que as normas nacionais e internacionais de informação e segurança alimentar sejam asseguradas após sua implementação, portanto, que sejam cumpridas e fiscalizadas. De nada adiantaria a confecção e assinatura das normas pelos países se não houver o papel cooperativo da iniciativa privada, sujeito das relaçóes econômicas. Isto porque contemporaneamente, o sujeito privado é também autor de normas, principalmente as de cunho econômico, que regem os mercados internacionais. Assim observam Gardella, Pardo e Döhmann (2015, p. 123):

Se han tendido puentes, dando paso así a um Estado y a una Administración más cooperativos com El sector privado y La sociedade civil. Se ha producido um nuevo reparto de papeles, una mayor separado? Interacción e implicación de las "partes". Y

4 A regulamentação de alimentos, e, portanto, a lei criminal sobre alimentos, gira em torno da proteção de três grandes interesses comuns: segurança alimentar e interesses econômicos dos consumidores. Nas últimas duas décadas, todos esses interesses jurídicos passaram por um processo de internacionalizaçáo muito significativo. [...]

A segurança alimentar corresponde a um interesse jurídico global, uma vez que está incluída no sistema universal de direitos humanos, nos termos do artigo 11 da Convenção Internacional sobre Direitos Econômicos, Sociais e Culturais das Naçóes Unidas (ICESCR). Seu núcleo garante o direito de estar livre de fome e acesso a alimentos adequados, o que envolve o direito à alimentação saudável. A consolidação do livre comércio como pilar da globalizaçấo levou a uma intensa regulaçâo internacional da segurança alimentar que estabelece as fronteiras para legisladores regionais. Além de proteger a saúde, visa impedir que a legislação doméstica dificulte injustificadamente o livre comércio com base na proteçâo da segurança alimentar. Assim, os principais promotores da legislação acima mencionada são, além da Food Agriculture Organization (FAO), da Organização Mundial do Comércio (OMC) e da autorregulaçáo corporativa. (traduçăoo livre) 
ello, naturalmente no deja de tener consecuencias sobre El Derecho administrativo El Derecho privado, otrora concebidos en términos antagónicos o "separatistas", para desembocar hoy en una interrelación y recíproca colaboración. ${ }^{5}$

Dessa maneira, o consumidor, diante dos produtos oferecidos pelo mercado - nacional ou internacional -, deve ser amparado por normas e políticas público-privadas que visem à segurança alimentar implementada pelo direito à informação. Tais políticas garantiriam, de diversas formas, a ciência necessária para optar por consumir ou náo determinado produto, por meio de iniciativas didáticas como rotulagem, propagandas, informativos, realização de debates, dentre outros.

\section{Conclusão}

A utilização de agrotóxicos causa impactos não só ao meio ambiente, mas também à saúde humana. $\mathrm{O}$ seu uso irrestrito não se trata de um problema pontual, mas de proporçóes globais. Apesar de sua fabricação e utilização se fundamentarem na garantia do abastecimento alimentar da populaçáo, evidencia-se também os interesses econômicos em todo o processo.

A Revolução Verde trouxe benefícios ao homem por meio do desenvolvimento científico e tecnológico de componentes capazes de enfrentar os obstáculos naturais, como mudanças climáticas e ataque de pragas, aumentando a produção agrícola. No entanto, esta não foi fiel ao seu discurso fundamentador, que era matar a fome no mundo, uma vez que este problema ainda afete vários países, estando distante de ser erradicado.

A referida revolução trouxe consigo o uso indiscriminado de agrotóxicos, contaminando alimentos consumidos pelo homem, além de causar danos à natureza. As pesquisas demonstram que várias doenças, desde as mais leves, até mesmo neoplasias graves e mortes são causadas pelo contato desses agentes no corpo humano. Apesar de existirem inúmeros métodos e açóes para redução da contaminação com agrotóxicos, como o controle biológico de pragas e doenças, a agricultura orgânica, a utilização de substâncias menos tóxicas e a capacitação técnica para a correta aplicação dos produtos, há muita resistência por parte dos produtores, motivada muitas vezes, por questôes econômicas.

A situação se agrava na medida em que os países têm políticas e normas jurídicas próprias de produção para o uso de agrotóxicos e organismos geneticamente

5 Pontes foram estabelecidas, dando lugar a um Estado e uma administraçấo mais cooperativa com o setor privado e a sociedade civil. Houve uma nova distribuição de papéis, uma maior interação e envolvimento das "partes". E isso, naturalmente, tem consequências sobre o direito administrativo e o direito privado, uma vez concebidos em termos antagônicos ou "separatistas", para terminar hoje com uma interrelação e colaboração recíproca (traducao livre). 
modificados. Ou seja, não há homogeneidade na proteção do consumidor final desses bens. Assim, cada produto encontrado nas prateleiras dos supermercados, derivado de países diferentes, possui um sistema de informação diversificado, de acordo com as regras do país de origem, gerando insegurança.

Com o fenômeno da globalização, houve um estreitamento de laços econômicos e sociais entre os países de forma que os sujeitos particulares passaram a estabelecer regras privadas para regulamentar essas relaçóes, além das públicas já existentes.

A abertura de fronteiras trouxe a facilidade de circulação de bens, dando aos consumidores a oportunidade de acesso aos produtos de outros países em mercados locais. Tal fenômeno, nunca antes ocorrido na história da humanidade, apesar das benesses e facilidades, encontra também obstáculos e prejuízos ao homem e à natureza no que diz respeito ao processo de produção desses produtos.

Independentemente do sistema de regulamentação adotado pelo país, deve-se salvaguardar o ser humano de possíveis contaminaçóes e doenças advindas dos agrotóxicos nestes alimentos, protegendo-se o direito fundamental à vida. Trata-se da garantia ao direito à informaçáo, previsto em diversas normas internacionais.

A cooperação internacional, com a implementação de normas uniformes públicas e privadas, determinando informaçóes a respeito dos produtos contendo agrotóxicos, garantirá a efetivação da segurança alimentar do consumidor a partir do seu direito de escolha entre consumir ou não determinado produto, avaliando sua origem e as substâncias componentes nele. Tais informaçóes devem ser disponibilizadas de modo verdadeiro, preciso e em linguagem adequada, livre de termos técnicos.

\section{Referências}

ALMEIDA, P. M. C.; CERINO, P. J. Responsabilidade do Estado nos danos ambientais causados pela utilização de agrotóxicos no Brasil. Revista Multidisciplinar Pey Këyo Científico. v. 4, n. 1. 2018. Disponível em: http://revistaadmmade.estacio.br/index.php/pkcroraima/article/view/5461. Acesso em: 28 abr. 2019.

ALMUSSA, A.; SCHMIDT, M. L. G. O contato com agrotóxicos e os possíveis agravos à saúde de trabalhadores rurais. Revista de Psicologia da UNESP, Assis, v. 8, n. 2, p. 184-188, 2009. Disponível em: http://seer.assis.unesp.br/index.php/ psicologia/article/view/1021. Acesso em: 26 abr. 2019.

ANVISA. Programa de Análise de Resíduos de Agrotóxicos em Alimentos - PARA. Relatório das análises de amostras monitoradas no período de 2013 a 2015. Disponível em: http://portal.anvisa.gov.br/documents/219201/2782895/Relat\%- 
C3\%B3rio+PARA/a6975824-74d6-4b8e-acc3-bf6fdf03cad0?version=1.0. Acesso em 28 de abr. 2019.

BARONAS, R. L. Agrotóxico versus pesticida: notas de leitura sobre polêmica e a memória discursiva Bakhtiniana. Revista de Estudos do Discurso, São Paulo, v. 14, n. 2, p. 62-87, 2019. Disponível em: https://www.scielo.br/pdf/bak/v14n2/21764573-bak-14-02-0062.pdf. Acesso em: 26 abr. 2019.

BECK, U. Sociedade de risco: rumo a uma outra modernidade. São Paulo: Editora 34, 2011.

BELCHIOR, D. C. V. et al. IMPACTOS DE AGROTÓXICOS SOBRE O MEIO AMBIENTE E A SAÚDE HUMANA. Cadernos de Ciência \& Tecnologia, Brasília, DF, v. 34, n. 1, p. 135-151, jan./abr. 2017. Disponível em: http://seer.sct. embrapa.br/index.php/cct/article/view/26296. Acesso em: 26 abr. 2019.

BORSOI, A. et al. Agrotóxicos: histórico, atualidades e meio ambiente. Acta Iguazu, v. 3, n. 1, p. 86-100, 2014. Disponível em: http://e-revista.unioeste.br/ index.php/actaiguazu/article/view/9650/7083. Acesso em 26 abr. 2019.

BRANGER, P.; TEODORO, N. S.; SILVEIRA, T. G. A sociedade de risco e a influência dos agrotóxicos. Mosaico Social - Revista do Curso de Ciências Sociais da UFSC. Ano VI, n. 06 - 2012: 201-215. Disponível em: https://cienciassociais. ufsc.br/files/2015/03/Artigo-124.pdf. Acesso em: 26 abr. 2019.

BRASIL. Presidência da República. Casa Civil. Subchefia para Assuntos Jurídicos. Lei n. 7.802, de 11 de julho de 1989. Dispóe sobre a pesquisa, a experimentaçáo, a produção, a embalagem e rotulagem, o transporte, o armazenamento, a comercialização, a propaganda comercial, a utilização, a importaçáo, a exportação, o destino final dos resíduos e embalagens, o registro, a classificação, o controle, a inspeção e a fiscalização de agrotóxicos, seus componentes e afins, e dá outras providências. Disponível em: http://www.planalto.gov.br/ccivil_03/LEIS/L7802. htm. Acesso em: 15 jul. 2020.

BRASIL. Presidência da República. Casa Civil. Subchefia para Assuntos Jurídicos. Decreto n. 4.074, de 4 de janeiro de 2002. Regulamenta a Lei no 7.802, de 11 de julho de 1989, que dispóe sobre a pesquisa, a experimentação, a produçáo, a embalagem e rotulagem, o transporte, o armazenamento, a comercialização, a propaganda comercial, a utilizaçáo, a importação, a exportação, o destino final dos resíduos e embalagens, o registro, a classificação, o controle, a inspeção e a fiscalização de agrotóxicos, seus componentes e afins, e dá outras providências. Disponível em: http://www.planalto.gov.br/ccivil_03/decreto/2002/D4074.htm. Acesso em: 15 jul. 2020. 
BRASIL. Agência Nacional de Vigilância Sanitária. Programa de Análise de Resíduos de Agrotóxicos em Alimentos (PARA). Brasília, DF: Anvisa, 2016. Disponível em: http://portal.anvisa.gov.br/documents/111215/0/Relat\%C3\%B3rio+PARA+2013-2015_VERS\%C3\%83O-FINAL.pdf/494cd7c5-5408-4e6a-b0e5-5098cbf759f8. Acesso em: 26 abr. 2019.

BRASIL. CONSEA. Conselho Nacional de Segurança Alimentar e Nutricional. Mesa de controvérsias sobre impactos dos agrotóxicos na soberania e segurança alimentar e nutricional e no direito humano à alimentação adequada: relatório final. Brasília, DF: Presidência da República, 2017.

BRIGNOL, V. M. et al. Representaçôes do risco causado pelo uso de agrotóxicos sobre a saúde e o ambiente, por agricultores convencionais e orgânicos da regiäo do Brejal, Petrópolis, RJ. Tese (Doutorado) - Escola Nacional de Saúde Pública Sergio Arouca, Fundação Oswaldo Cruz, Rio de Janeiro, 2012.

BULL, D.; HATHAWAY, D. Pragas e venenos: agrotóxicos no Brasil e no terceiro mundo. In: BULL, D.; HATHAWAY, D. Pragas e venenos; agrotoxicos no Brasil e no terceiro mundo. Petrópolis: Vozes, 1986.

CARNEIRO, F. F. et al. Dossiê ABRASCO: um alerta sobre os impactos dos agrotóxicos na saúde. Rio de Janeiro/São Paulo: EPSJV/Expressão Popular, 2015. Disponível em: https://www.arca.fiocruz.br/bitstream/icict/26221/2/Livro\%20 EPSJV\%20013036.pdf. Acesso em: 25 abr. 2019.

EHLERS, E. Agricultura sustentável: origens e perspectivas de um novo paradigma. São Paulo : Livros da Terra, 1996.

FAO - FOOD AND AGRICULTURE ORGANIZATION OF THE UNITED NATIONS. Plan de Acción de la Cumbre Mundial sobre la Alimentación. Roma. 1996. Disponível em: http://www.fao.org/docrep/003/w3613s/w361s00.thm. Acesso em 28 abr. 2019.

FARIA, M. V. C. Avaliação de ambientes e produtos contaminados por agrotóxicos. In: PERES, F.; MOREIRA, J. C. (orgs.). É veneno ou é remédio? - agrotóxicos, saúde e ambiente. Rio de Janeiro: Fiocruz, 2003. p. 177-209.

GARCIA, E. G.; ALVES FILHO, J. P. Aspectos de prevenção e controle de acidentes no trabalho com agrotóxicos. São Paulo. Fundacentro, 2005.

GARDELLA, M. M. D.; PARDO, J. E.; DÖHMANN, I. S. Estrategias del Derecho ante la incertidumbre y la globalización. Madrid: Marcial Pons, 2015.

HOLANDA. Convenção de Roterdã. 2009. Disponível em: https://www.mma. 
gov.br/estruturas/smcq_seguranca/_arquivos/roterd_texto_143.pdf. Acesso em: 11 jun. 2020.

HUPFFER, H. M.; POL, J. J. O direito de escolha do consumidor e a necessária informação sobre alimentos com agrotóxicos. Nomos, Fortaleza, v. 37, n. 2, p. 41-67, jul./dez. 2017. Disponível em: http://www.periodicos.ufc.br/nomos/article/ view/5509. Acesso em: 26 abr. 2019.

LONDRES, F. Agrotóxico no Brasil: um guia para a ação em defesa da vida. Rio de Janeiro/Fortaleza: ANA/RBJA, 2011. Disponível em: https://br.boell.org/pt-br/2011/10/31/agrotoxicos-no-brasil-um-guia-para-acao-em-defesa-da-vida-0. Acesso em: 26 abr. 2019.

MARTÍN, A. N. General report on food regulation and criminal law. In: MARTÍN, A. N.; QUACKELBEEN, L.; SIMONATO, M. (eds.). Food regulation and criminal justice. Antwerpen: Maklu, 2016. p. 17-64.

MATOS, P. H. F. et al. Estudo epidemiológico das intoxicaçôes por agrotóxicos no Brasil. Mostra Cientifica da Farmácia, v. 5, mar. 2019. Disponível em: http:// publicacoesacademicas.unicatolicaquixada.edu.br/index.php/mostracientificafarmacia/article/view/2985. Acesso em: 24 abr. 2019.

MORAGAS, W. M.; SCHNEIDER, M. O. Biocidas: suas propriedades e seu histórico no Brasil. Caminhos de Geografia, Uberlândia, v. 3, n. 10, p. 26-40, 2003. Disponível em: http:/www.seer.ufu.br/index.php/caminhosdegeografia/article/ view/15315. Acesso em 25 abr. 2019.

MOURA, R. M. Rachel Carson e os agrotóxicos: 45 anos após primavera silenciosa. Anais da Academia Pernambucana de Ciência Agronômica, v. 5, p. 4452, 2013. Disponível em: http://www.ead.codai.ufrpe.br/index.php/apca/article/ download/188/170. Acesso em: 26 abr. 2019.

NUNES, G. S.; RIBEIRO, M. L. Pesticidas: uso, legislação e controle. Pesticidas: Revista de Ecotoxicologia e Meio Ambiente, Curitiba, v. 9, 1999. Disponível em: https://revistas.ufpr.br/pesticidas/article/view/39601. Acesso em: 26 abr. de 2019.

ONU - ORGANIZAÇÃO DAS NAÇÕES UNIDAS. Conferência das Nações Unidas sobre Meio Ambiente e Desenvolvimento. 1992.

ONU - ORGANIZAÇÃO DAS NAÇÓES UNIDAS. Convenção sobre Diversidade Biológica. 1993.

OPAS - ORGANIZAÇÃO PAN-AMERICANA DE SAÚDE. Manual de Vigilância da Saúde de Populaçóes Expostas a agrotóxicos. Ministério da Saúde, Secretaria de Vigilância Sanitária. Brasília: OPAS, 1996. 
OPAS - ORGANIZAÇÃO PAN-AMERICANA DE SAÚDE. Intoxicações agudas por agrotóxicos. Atendimento inicial do paciente intoxicado. Ministério da Saúde, Secretaria de Vigilância Sanitária. Brasília: OPAS, 2018.

PASCHOAL, A. D. Praga, praguicida e a crise ambiental: problemas e soluçóes. Rio de Janeiro: Fundação Getúlio Vargas, 1979.

PERLINGEIRO, R. A codificação do direito à informação na América Latina (The Codification of the Right of Access to Information in Latin America). Revista de Direito Administrativo e Constitucional - $A \& C$, Belo Horizonte, ano 14, n. 56, p. 209-227, abr./jun. 2014. Disponível em: http://www.revistaaec.com/index.php/ revistaaec/article/view/99. Acesso em: 25 abr. 2019.

PINOTTI, M. M. Z.; SANTOS, J. C. P. From the ancient times of the agriculture to the biological control in plants: a little of the history. Ciência Rural, Santa Maria, v. 43, n. 10, p. 1797-1803, 2013. Disponível em: https://www.scielo.br/ scielo.php?pid=S0103-84782013001000011\&script=sci_arttext. Acesso em: 26 abr. 2019.

PIGNATI, W. Uso de agrotóxicos no Brasil: Perspectiva da saúde do trabalhador e ambiental. W Pignati - Rev. Bras. Med. Trab, v. 16, p. 1-44, 2018 Disponível em: http://www.rbmt.org.br/export-pdf/347/v16s1a19.pdf. Acesso em: 24 abr. 2019.

PORTO, M. F.; MILANEZ, B. Eixos de desenvolvimento econômico e geração de conflitos socioambientais no Brasil: desafios para a sustentabilidade e a justiça ambiental. Ciência \& Saúde Coletiva, Rio de Janeiro, v. 14, n. 6, p. 1983-1994, 2009. Disponível em: http://www.scielo.br/scielo.php?pi$\mathrm{d}=$ S1413-81232009000600006\&script=sci_arttext\&tlng=es. Acesso em: 25 abr. 2019 .

QUEIROZ, M. A. C.; GUEDES, C. A. M.; ASSIS, R. L. A atuação dos voluntários do programa ProHuerta em Río Cuarto (Córdoba, Argentina) na formação de hortas e difusão dos conceitos de agricultura orgânica e agroecologia. Revista de la Facultad de Agronomi. v. 117, n. 1, p. 43-52, 2018. Disponível em: http://sedici. unlp.edu.ar/handle/10915/70864. Acesso em: 25 abr. 2019.

RIBAS, P. P.; MATSUMURA, A. T. S. A química dos agrotóxicos: impactos sobre a saúde e meio ambiente. Revista Liberato, Novo Hamburgo, v. 10, n. 14, p. 149158, jul./dez., 2009. Disponível em: http://www.liberato.com.br/sites/default/ files/arquivos/Revista_SIER/v.\%2010,\%20n.\%2014\%20(2009)/3.\%20A\%20 qu\%EDmica\%20dos\%20agrot\%F3xicos.pdf. Acesso em: 23 abr. 2019.

ROCHA, J. C. C. Segurança alimentar na era biotecnológica. Revista Internacional 
de direito e Cidadania, Florianópolis, n. 4, p. 97-107, jun. 2009. Disponível em: http://www.egov.ufsc.br/portal/conteudo/seguran\%C3\%A7-alimentar-na-erabiotecnol\%C3\%B3gica. Acesso em: 26 abr. 2019.

SERRA, L. S. et al. Revolução Verde: reflexôes acerca da questão dos agrotóxicos. REVISTA DO CEDS, Goiânia, v. 1, n. 4, p. 2-25, jan./jul. 2016. Disponível em: http://professor.pucgoias.edu.br/sitedocente/admin/arquivosUpload/6461/material/revolu\%C3\%A7\%C3\%A3o_verde_e_agrot\%C3\%B3xicos_-_marcela_ruy_ f\%C3\%A9lix.pdf. Acesso em: 26 abr. 2019.

SIEBENEICHLER, A. J. A atuação estatal frente ao desenvolvimento de mercado alternativo de alimentos: Análise comparativa entre os incentivos brasileiro e europeu ao mercado de alimentos orgânicos. Revista Destaques Acadêmicos, Lajeado, v. 10, n. 1, p. 186-197, 2018. Disponível em: http://www.univates.br/revistas/ index.php/destaques/article/view/1769/1316. Acesso em: 26 abr. 2019.

SILVA NETO, B. A questão agroecológica: uma perspectiva ecossocialista. Curitiba: CRV, 2017.

STOPPELLI, I. M. B. S.; MAGALHĀES, C. P. Saúde e segurança alimentar: a questão dos agrotóxicos. Ciência \& Saúde Coletiva, Rio de Janeiro, v. 10, p. 91 100, 2005. Disponível em: http://www.scielo.br/scielo.php?script=sci_arttext\&pid=\$1413-81232005000500012\&lng=en\&nrm=iso. Acesso em 26 abr. 2019.

SUIÇA. Convenção da Basiléia. 1989. Disponível em: http://www.basel.int/Home/ tabid/2202/mctl/ViewDetails/EventModID/8051/EventID/330/xmid/8052/ Default.aspx. Acesso em: 26 abr. 2019.

TEIXEIRA, T. M. Saúde e direito à informação: o problema dos agrotóxicos nos alimentos. Revista de Direito Sanitário, São Paulo, v. 17, n. 3, p. 134-159, 2017. Disponível em: https://doi.org/10.11606/issn.2316-9044.v17i3p134-159. Acesso em: 25 abr. 2019.

UNITED NATIONS. Resolution 30/248. Guidelines for consumer protection. New York, 2003 a. Disponível em: https://www.un.org/esa/sustdev/publications/consumption_en.pdf. Acesso em: 18 abr. 2019.

UNITED NATIONS. Resolution 39/248. Guidelines for consumer protection. New York, 2003b. Disponível em: https://www.un.org/esa/sustdev/publications/consumption_en.pdf. Acesso em: 18 abr. 2019.

VELASCO, L. O. M.; CAPANEMA, L. X. L. O setor de agroquímicos. BNDES Setorial, Rio de Janeiro, n. 24, p. 69-96, 2006. Disponível em: https://web.bndes. gov.br/bib/jspui/handle/1408/4643. Acesso em: 28 abr.2019. 
WARD, M. H. et al. Identifying populations potentially exposed to agricultural pesticides using remote sensing and a Geographic Information System. Environmental Health Perspectives, v. 108, n. 1, p. 5-12, 2000. Disponível em: https://ehp. niehs.nih.gov/doi/abs/10.1289/ehp.001085. Acesso em: 26 abr. 2019. 